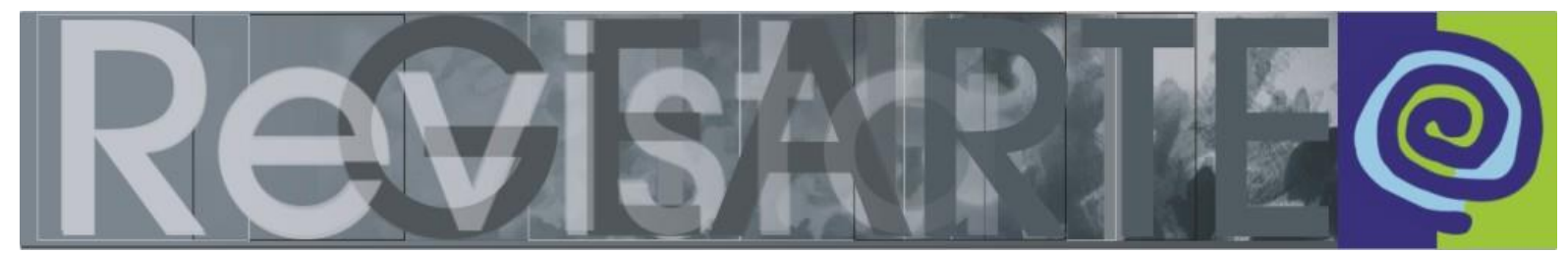

ISSN 2357-9854 | e-ISSN 2596-3198 (online)

\title{
Artes visuais e design de interiores: iconografia e o conceito de projeto
}

\author{
Aarão Pereira de Araújo Júnior \\ (Instituto Federal de Educação, Ciência e Tecnologia da Paraíba - IFPB, \\ João Pessoa/PB, Brasil) \\ Robson Xavier da Costa \\ (Universidade Federal da Paraíba - UFPB, João Pessoa/PB, Brasil)
}

\begin{abstract}
RESUMO - Artes visuais e design de interiores: iconografia e o conceito de projeto - Este trabalho tem como objetivo analisar o impacto das artes visuais no desenvolvimento do conceito de projeto nas disciplinas do eixo central do Curso Superior de Tecnologia em Design de Interiores do Instituto Federal da Paraíba - CSTDI/IFPB a partir da análise do processo de um minicurso experimental desenvolvido no Instituto Federal da Paraíba (IFPB) em 2017, avaliando a utilização dos elementos da linguagem visual aplicados ao conceito de projeto para design de interiores. $O$ problema de pesquisa é: os elementos da linguagem visual proporcionam o aprofundamento da compreensão do conceito de projeto de design de interiores nas disciplinas do eixo central do Curso de Graduação em Design de interiores do IFPB? Os resultados mostraram que a análise por meio da descrição pré-iconográfica (PANOFSKY, 1986) pode ser uma ferramenta para a compreensão do conceito de projeto de design de interiores no contexto analisado.
\end{abstract}

PALAVRAS-CHAVE

Artes visuais. Design de interiores. Conceito de projeto. Análise pré-iconográfica.

\begin{abstract}
Visual arts and interior design: iconography and the project concept -This work aims to analyze the impact of the visual arts in the development of the concept of project in the disciplines of the central axis of the Higher Course of Technology in Interior Design of the Federal Institute of Paraíba - CSTDI/ IFPB from the analysis of the process of an experimental minicourse developed at the Federal Institute of Paraíba (IFPB) in 2017, evaluating the use of visual language elements applied to the design concept for interior design. The research problem is: do visual language elements provide a deeper understanding of the concept of interior design project in the core disciplines of the IFPB Interior Design Undergraduate Course? The results showed that the analysis through the pre-iconographic description (PANOFSKY, 1986) can be a tool for understanding the concept of interior design project in the analyzed context.
\end{abstract}

\section{KEYWORDS}

Visual arts. Interior design. Concept of design. Pre-iconographic analysis.

RESUMEN - Artes visuales y diseño de interiores: iconografía y el concepto de diseño Este trabajo tiene como objetivo analizar el impacto de las artes visuales en el desarrollo del concepto de diseño en las disciplinas del eje central del Curso Superior de Tecnología en Diseño de Interiores en el Instituto Federal da Paraíba - CSTDI / IFPB a partir del análisis del proceso de un mini curso experimental desarrollado en el Instituto Federal de Paraíba (IFPB) en 2017, evaluando el uso de elementos del lenguaje visual aplicados al concepto de diseño para diseño de interiores. El problema de investigación es: ¿los elementos del lenguaje visual proporcionan una comprensión más profunda del concepto de diseño de interiores en las disciplinas del eje central del Curso de Pregrado en Diseño de Interiores en IFPB? Los resultados mostraron que el análisis a través de la descripción pre-iconográfica (PANOFSKY, 1986) puede ser una herramienta para comprender el concepto de proyecto de diseño de interiores en el contexto analizado.

PALABRAS CLAVE

Artes visuales. Diseño de interiores. Concepto del proyecto. Análisis pre-iconográfico.

ARAÚJO JÚNIOR, Aarão Pereira de; COSTA, Robson Xavier da. 


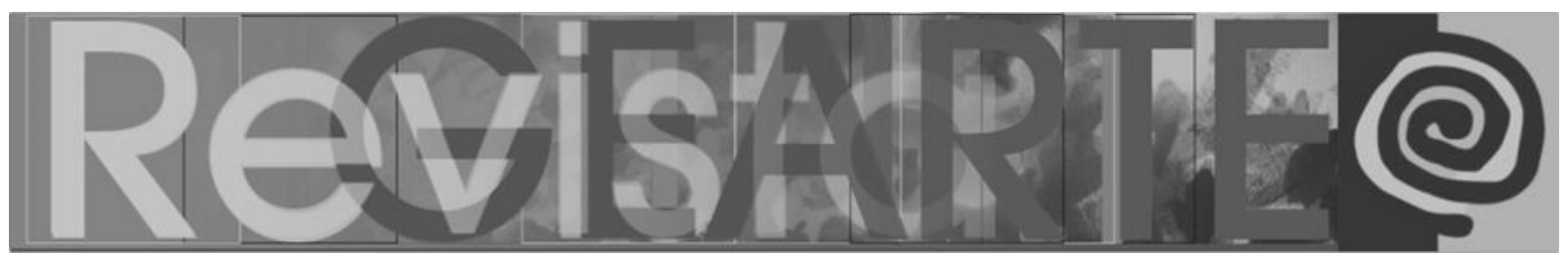

\section{Introdução}

A atenção com a observação deve ser inerente à concepção do conceito de projeto para o designer de interiores. Nesse processo, muitas vezes, o designer busca a inspiração em um tema determinado pelo cliente, ou pela pesquisa desenvolvida diante de uma problemática específica, a qual visa obter um conceito e um partido arquitetônico que irá guiar todo o desenvolvimento projetual, por meio das formas, cores, texturas, materiais, etc.

No Curso de graduação Superior de Tecnologia em Design de Interiores do Instituto Federal da Paraíba (CSTDI/IFPB), a base principal da formação profissional do estudante é a expressão gráfica, por meio de disciplinas como desenho técnico, desenho arquitetônico, detalhamento de projetos, etc. As artes visuais, ou mais especificamente os elementos da linguagem visual, estão presentes nas seguintes disciplinas desse curso: desenho de observação, oficina de plástica, modelos e maquetes e cor. As disciplinas citadas fazem parte do eixo central do curso, a oficina de plástica é o componente curricular que mais aborda os elementos da linguagem visual, por meio de atividades práticas e de pesquisas com as artes visuais, objetivando estimular o desenvolvimento do potencial criativo do estudante no $1^{\circ}$ período do curso, de maneira a inseri-lo na trajetória das disciplinas voltadas para o projeto de interiores.

Outras disciplinas como história do design, história das artes e da arquitetura e história do mobiliário introduzem os estudantes nos conceitos e abordagens artísticas objetivando ampliar o conhecimento e o repertório dos mesmos em relação às artes visuais e sua história, para utilização nos futuros projetos de design de interiores. Os elementos da linguagem visual presentes na prática das disciplinas citadas podem favorecer a interatividade e transformação do ambiente de ensino aprendizagem no IFPB, instituição de ensino formal oriunda da tradição do ensino técnico e tecnológico aplicado no Brasil. 


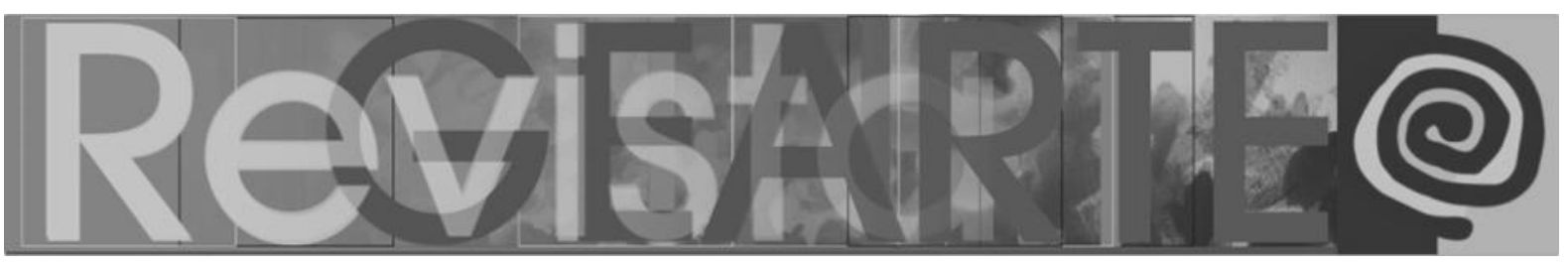

Partimos do seguinte problema de pesquisa: os elementos da linguagem visual proporcionam o aprofundamento da compreensão do conceito de projeto de design de interiores nas disciplinas do eixo central do Curso de Graduação em Design de interiores (CSTDI) do IFPB?

Os elementos das artes visuais, utilizados como propulsores do desbloqueio do potencial criativo dos estudantes nas disciplinas do eixo central do Curso de Graduação em Design de Interiores do IFPB, merecem uma maior investigação em relação a sua influência nas outras disciplinas do CSTDI.

A busca da atualização do currículo nos cursos de graduação tecnológicos no Brasil visa possibilitar novos meios de produção e aprendizagem para os estudantes favorecendo a autonomia e aprimorando o contato com as novas tecnologias aplicadas ao design de interiores.

Esta pesquisa buscou responder o problema de pesquisa a partir da investigação no campo empírico procurando confirmar a seguinte hipótese: o ensino das Artes Visuais proporciona o aprofundamento da compreensão do conceito de projeto de design de interiores nas disciplinas do eixo central do Curso de Graduação em Design de interiores do IFPB.

Para isso objetivamos analisar o impacto do estudo dos elementos da linguagem visual no desenvolvimento do conceito de projeto nas disciplinas do eixo central do CSTDI/IFPB. Analisamos o processo experimental aplicado no minicurso "utilização dos elementos das artes visuais como conceito de projeto para design de interiores" oferecido no IFPB em 2017.

Para atingirmos o objetivo foi necessária a realização de observação direta participante, estando o pesquisador em situação de espaço e tempo, que lhe permitiu assistir as manifestações do fenômeno a ser estudado, podendo utilizar vários tipos de registros de suas observações. O local escolhido para a pesquisa de campo foi o CSTDI/IFPB, Campus João Pessoa. No curso tivemos estudantes 


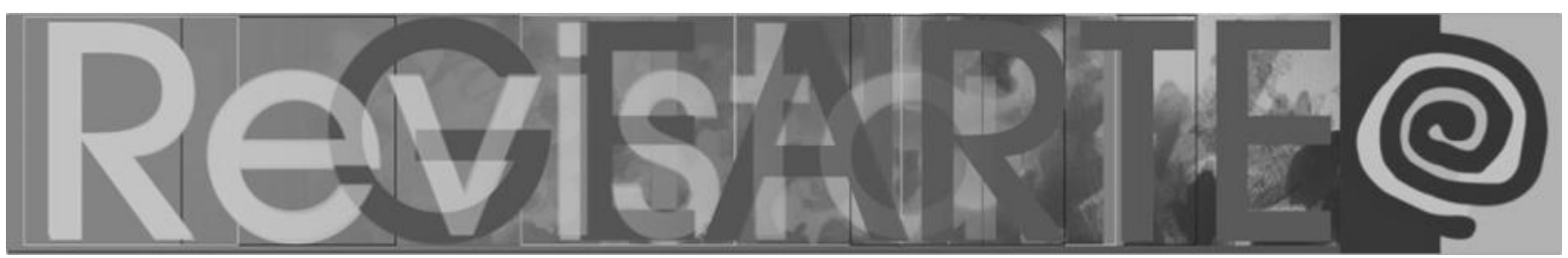

do CSTDI/IFPB que estavam cursando as seguintes disciplinas: oficina de plástica, 1 período letivo; metodologia de projetos, $2^{0}$ período; projeto de interiores residenciais, $3^{\circ}$ período; projeto de Interiores comerciais e serviços, 4ำ período; projeto de interiores institucionais, $5^{\circ}$ período e projeto de graduação, $6^{\circ}$ período.

As etapas metodológicas utilizadas nesta pesquisa foram: (1) caracterização do objeto de estudo por meio de pesquisa bibliográfica; (2) observação direta e aplicação de questionários com estudantes; (3) entrevista semiestruturada com professor de uma disciplina do eixo central; (4) prática de ensino: por meio da aplicação de minicurso, que permitiu a visualização da utilização do conceito projetual, por meio das Artes Visuais.

O minicurso foi desenvolvido no decorrer da pesquisa, por depender exclusivamente dos resultados da observação direta. As falas dos atores foram registradas, catalogadas e foram feitas avaliações com o objetivo de verificar se houve contribuição efetiva das Artes Visuais para o projeto de design de interiores.

\section{Iconografia e descrição pré-iconográfica}

De acordo com Oliveira e Garcez (2001), as obras de arte expressam pensamentos, visões de mundo e podem provocar inquietações, sensações e estimular a sensibilidade do espectador. Para interagir e apreciar imagens, o leitor utiliza informações de experiências anteriores, percepção, habilidades comunicativas, visuais, espaciais, informações, sensibilidade e imaginação (OLIVEIRA e GARCEZ, 2001, p. 20).

Para apreciar a arte e ler imagens precisamos estimular e desenvolver a observação. Fator que depende do interesse (...), não apenas para apreciar as imagens da arte, mas também para a vida prática (OLIVEIRA e GARCEZ, 2001, p. 26-27).

No minicurso realizado no CSTDI/IFPB trabalhamos com o método iconográfico de leitura de imagens. Segundo Panofsky (1986), iconografia é o ramo 


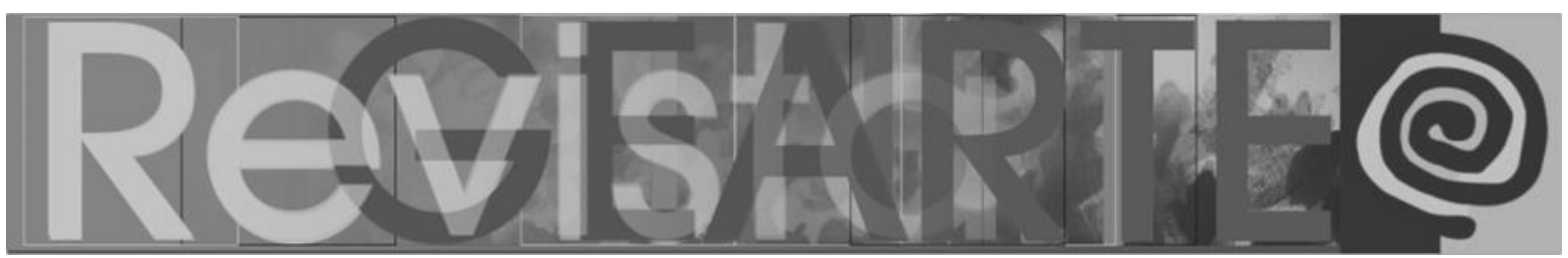

da história da arte que trata do tema ou mensagem das obras de arte em contraposição à sua forma. Implica um método de proceder puramente descritivo, ou até mesmo estatístico. A iconografia é, portanto, a descrição e classificação das imagens enfocando o tema.

Os objetos e fatos identificados poderão produzir uma reação em quem está fazendo a leitura da imagem. A essa reação, por ser emocional e psicológica, chamaremos de significado expressional e difere do fatual por ser apreendido, não por simples identificação, mas por "empatia". Dessa maneira, tanto o significado expressional como o fatual podem classificar-se juntos: constituem a classe dos significados primários ou naturais (PANOFSKY, 1986).

Segundo Panofsky (1986) para efetuarmos a leitura de uma obra de arte, podemos classificar os significados em três níveis:

1. Tema primário ou natural, subdividido em fatual e expressional. É apreendido pela identificação das formas puras, ou seja: certas configurações de linha e cor, ou determinados pedaços de bronze ou pedra de forma peculiar, como representativos de objetos naturais tais que seres humanos, animais, plantas, casas, ferramentas e assim por diante (...). Uma enumeração desses motivos constituiria uma descrição pré-iconográfica de uma obra de arte.

2. Tema secundário ou convencional: é apreendido pela percepção de que uma figura masculina com uma faca representa São Bartolomeu, que uma figura feminina com um pêssego na mão é a personificação da Veracidade, que um grupo de figuras, sentadas a uma mesa de jantar numa certa disposição e pose, representa a Última Ceia, ou que duas figuras combatendo entre si, numa dada posição, representam a Luta entre o Vício e a Virtude. Assim fazendo, ligamos os motivos e as combinações de motivos artísticos composições com assuntos e conceitos.

3. Significado intrínseco ou conteúdo: é apreendido pela determinação daqueles princípios subjacentes que revelam a atitude básica de uma nação, de um período, classe social, crença religiosa ou filosófica qualificados por uma personalidade e condensados numa obra (PANOFSKY, 1986).

Para esta pesquisa utilizamos a descrição pré-iconográfica das imagens, por entender que essa análise foi suficiente para identificarmos os elementos visuais essenciais, que servem de base na elaboração do conceito de projeto de design de interiores.

ARAÚJO JÚNIOR, Aarão Pereira de; COSTA, Robson Xavier da. 


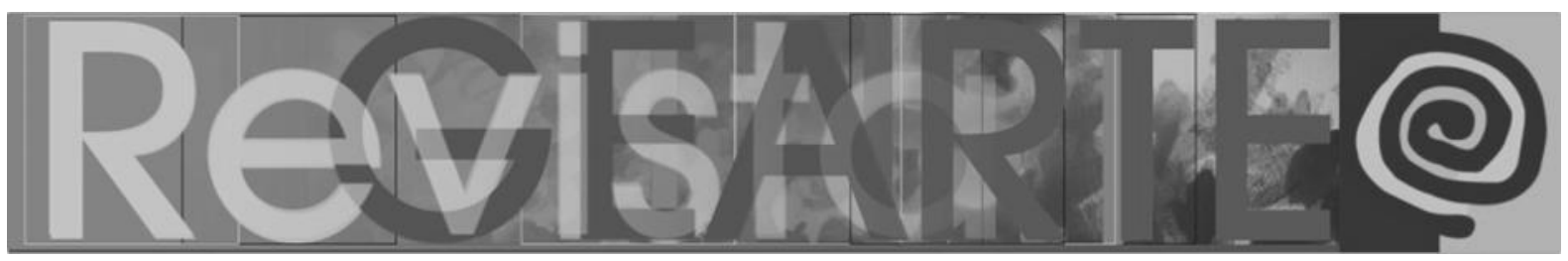

\title{
O conceito de projeto de design de interiores
}

Para Higgins (2015), um projeto de design de interiores geralmente é conduzido por uma ideia principal chamada "conceito". Um conceito pode ser definido como uma ideia abstrata ou geral que contribui para as decisões tomadas durante o processo de projeto, de modo que o resultado construído se torne coeso. Um conceito pode se relacionar com o projeto inteiro e afetar todos os aspectos de tomadas de decisão, ou pode ser aplicado a uma parte particular do processo de projeto (HIGGINS, 20015, P 36).

Para Meira (2017), conceito é a ideia principal do projeto, é ele que fundamenta a sua concepção, revelando as intenções do designer em relação ao tema proposto. $\mathrm{O}$ conceito sintetiza a mensagem que o designer pretende transmitir por meio do projeto. A formulação do conceito pode partir de uma intepretação do cliente, do programa de necessidades, do local onde o projeto será realizado, de uma abordagem de design, dentre outros elementos. Conforme Meira ${ }^{1}$,

\begin{abstract}
Não há uma fórmula para este tipo de formulação de conceito, o processo é livre. Mas pode partir de releituras, de analogias etc. As obras de arte podem contribuir para incrementar e fundamentar o repertório visual do designer, o que, por sua vez, contribui para a formulação de conceitos, independente de estes terem ou não relação direta com as artes visuais. Acredito que quanto melhor o repertório visual do designer, maior a sua facilidade de construir analogias e formular conceitos (MEIRA, 2017).
\end{abstract}

Segundo Gibbs (2010), o designer de interiores ${ }^{2}$ pode solicitar ao cliente, por exemplo, três palavras que transmitam as características desejadas, como

1 Entrevista concedida por Flora Meira a Aarão Pereira de Araújo Júnior por e-mail, em João Pessoa/PB, 18 de junho de 2017.

2 De acordo com o Catálogo Nacional de Cursos Superiores de Tecnologia (2016), Design de Interiores é a profissão na qual o profissional: cria e desenvolve projetos de espaços internos, considerando fatores estéticos, simbólicos, ergonômicos, socioculturais e produtivos. Realiza pesquisa de tendências. Planeja, desenvolve e gerencia projetos de interiores com o uso de materiais e recursos sustentáveis. Desenha, representa e expressa o projeto de interiores graficamente de forma bi e tridimensional. Elabora maquetes e modelos volumétricos com uso de técnicas diferenciadas de expressão gráfica. Avalia e emite parecer técnico em sua área de formação (BRASIL/CNCST, 2016). 


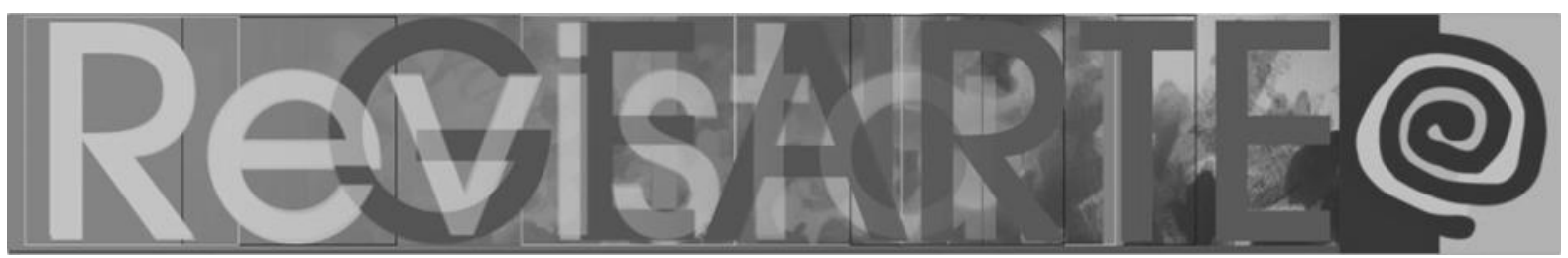

leveza, elegância e conforto. Outros profissionais podem buscar inspiração nos elementos naturais próprios do local onde o imóvel se localiza, talvez colocando terra, folhas ou pedras do jardim sobre a mesa de trabalho, para captar cores e texturas. Por outro lado, os dados obtidos do programa de necessidades ${ }^{3}$ podem servir como ponto de partida para o desenvolvimento do conceito de projeto.

O PMBOK (2008) afirma que um projeto consiste em um esforço transitório, com início e fim, com o objetivo de desenvolver um único produto, serviço ou resultado, enquanto Valle et. al. (2007) afirmam que um projeto é algo único e também transitório, que objetiva atingir suas metas e ser concretizado.

Mas, como expressar essa ideia de modo que possibilite ao designer de interiores concretizá-la em seu projeto? Para Gibbs (2010), essa ferramenta pode ser apresentada na forma de painéis.

Alguns designers de interiores formalizam seus conceitos em painéis que são apresentados à empresa ou ao cliente. Os painéis conceituais (Figura 1) permitem comunicar com sucesso a essência do projeto, o que uma apresentação convencional de materiais não possibilita.

Figura 1 - Exemplo de um Painel conceitual

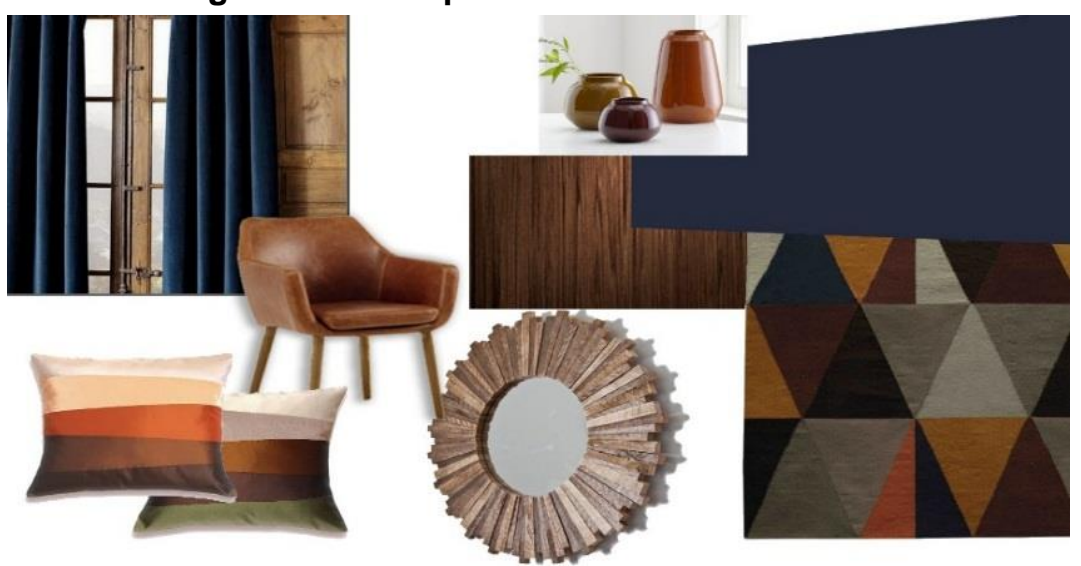

Fonte: www.pinterest.com.br

3 Programa que estabelece o âmbito de possibilidades da forma e, ao mesmo tempo, atua como elemento de verificação do projeto em diversas fases do seu processo (PIÑÓN, 2006 p. 50).

ARAÚJO JÚNIOR, Aarão Pereira de; COSTA, Robson Xavier da.

322

Artes visuais e design de interiores: iconografia e o conceito de projeto.

Revista GEARTE, Porto Alegre, v. 7, n. 2, p. 316-333, maio/ago. 2020.

Disponível em: http://seer.ufrgs.br/gearte 


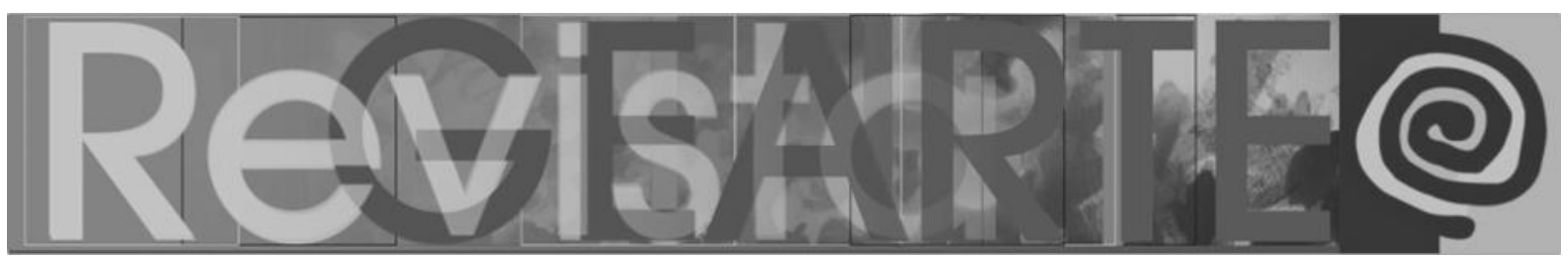

Esses painéis costumam ser feitos com colagem, reunindo recortes de panfletos, jornais, revistas, fotografias e croquis, que expressam a proposta que 0 designer de interiores tem em mente. Imagens e diferentes combinações de cores podem ser extraídas de uma grande variedade de fontes, mesmo as que não se relacionam diretamente com o design de interiores, como imagens de jardins, moda ou culinária (GIBBS, 2010).

A partir da interpretação do briefing 4 os grupos devem sintetizar o conceito no interior de um cubo de $30 \times 30 \times 30 \mathrm{~cm}$, de maneira livre. 0 conceito definido nesta atividade deve permear todo o desenvolvimento do projeto comercial (MEIRA, 2017).

Utilizamos definição de Gibbs (2010) para a formulação do conceito para o projeto de design de interiores. Propomos a seguinte definição do conceito aplicado ao projeto de design de interiores: "expressão sintética de uma representação das características gerais de um objeto a ser projetado". Desse modo, o conceito utilizado neste trabalho contempla as áreas de Designer de Interiores e Artes Visuais.

\section{O Curso Superior de Tecnologia em Design de Interiores do IFPB}

O Curso Superior de Tecnologia em Design de Interiores (CSTDI) do IFPB, Campus João Pessoa, tem em sua matriz curricular uma gama de disciplinas voltadas para a profissionalização do design de interiores. Tem como objetivo formar profissionais para atuar na elaboração de projetos de interiores, considerando aspectos funcionais, estéticos, ergonômicos, tecnológicos, socioeconômicos, ambientais, culturais e históricos, visando atender as necessidades dos usuários dos espaços internos/ambientes interiores (IFPB, 2015). O Tecnólogo de Nível Superior em Design de Interiores está habilitado a

4 Segundo Sant'Anna (1989, p.109), chama-se briefing todas as informações preliminares que contém as instruções que o cliente fornece para orientar os seus trabalhos. É um conjunto de dados fornecidos para o desenvolvimento de um trabalho, geralmente utilizado em áreas como administração, arquitetura e por profissionais da comunicação, como relações públicas e publicitários. Ele permite um mapeamento do problema, para que a partir dele, seja feito um roteiro de ação, com o objetivo de gerar soluções. 


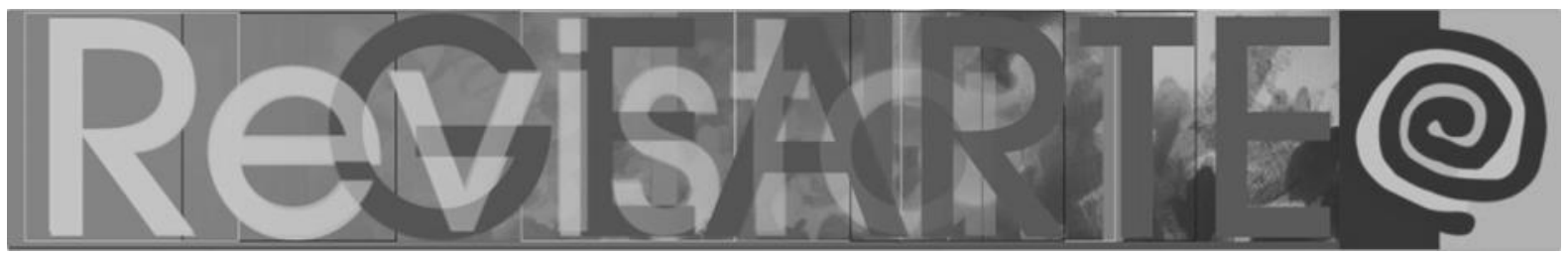

elaborar projetos de interiores residenciais, comerciais e institucionais; elaborar layouts de projetos de interiores; desenvolver projetos de interiores residenciais, comerciais e institucionais; detalhar projetos de interiores considerando os elementos que compõem os ambientes interiores: mobiliários, revestimentos, forros; analisar espaços interiores considerando aspectos funcionais, estéticos, entre outros.

A matriz curricular do CSTDI/IFPB está disposta de forma horizontal, de modo que se tenha uma linha básica de disciplinas de formação de Projeto de Interiores (disciplinas no quadro amarelo), em que as outras disciplinas do curso, classificadas em disciplinas de formação teórica (disciplinas no quadro laranja) e disciplinas de formação profissional (disciplinas no quadro verde), se integrem em seis semestres, permitindo a prática interdisciplinar, conforme se verifica na Figura 2. As disciplinas no quadro de cor cinza são optativas e de atividades complementares (ARAÚJO JÚNIOR, 2015, p. 151).

Figura 2 - Matriz curricular do Curso Superior de Tecnologia em Design de Interiores do IFPB

\begin{tabular}{|c|c|c|c|c|c|}
\hline 1 semestre & 2 semestre & 3 semestre & 4 semestre & 5 semestre & 6 semestre \\
\hline Plástica & $\begin{array}{l}\text { Metodologia } \\
\text { de Projetos }\end{array}$ & \begin{tabular}{|l|} 
Proj Interiores \\
Residenciais \\
\end{tabular} & \begin{tabular}{|l|} 
Proj Interiores \\
Com e Servicos
\end{tabular} & \begin{tabular}{|l|} 
Proj Interiores \\
Institucionais
\end{tabular} & $\begin{array}{l}\text { Projeto de } \\
\text { Graduação }\end{array}$ \\
\hline $\begin{array}{l}\text { Desenho } \\
\text { Técnico }\end{array}$ & $\begin{array}{l}\text { Desenho } \\
\text { Arquitetônico }\end{array}$ & \begin{tabular}{|l|}
$\begin{array}{l}\text { Detalhamento } \\
\text { de Projetos }\end{array}$ \\
\end{tabular} & CAD 2D & CAD 3D & $\begin{array}{l}\text { Tratamento } \\
\text { de Imagens }\end{array}$ \\
\hline $\begin{array}{l}\text { Desenho de } \\
\text { Observação }\end{array}$ & $\begin{array}{l}\text { Desenho } \\
\text { Perspectivo }\end{array}$ & $\begin{array}{l}\text { Instalações } \\
\text { Prediais }\end{array}$ & Iluminação & Acústica & \begin{tabular}{|l|} 
Prática e Ética \\
Profissional
\end{tabular} \\
\hline $\begin{array}{l}\text { Organização } \\
\text { Espacial }\end{array}$ & $\begin{array}{l}\text { Modelos e } \\
\text { Maquetes }\end{array}$ & $\begin{array}{l}\text { Conforto } \\
\text { Térmico }\end{array}$ & Ecodesign & $\begin{array}{l}\text { Orçamento e } \\
\text { Geren. Obras }\end{array}$ & \begin{tabular}{|l|} 
Formação de \\
Empreend.
\end{tabular} \\
\hline $\begin{array}{l}\text { História do } \\
\text { Design }\end{array}$ & Ergonomia & Materiais & $\begin{array}{l}\text { Cultura } \\
\text { Brasileira }\end{array}$ & \begin{tabular}{|l|} 
Metodologia \\
Científica
\end{tabular} & \begin{tabular}{|l|} 
Atividades \\
Complement.
\end{tabular} \\
\hline Cor & $\begin{array}{l}\text { História da } \\
\text { Arte e Arq. }\end{array}$ & $\begin{array}{l}\text { História do } \\
\text { Mobiliário }\end{array}$ & & & Libras \\
\hline
\end{tabular}

Fonte: acervo dos autores (2015).

As disciplinas destacadas em amarelo são as que compõem o eixo central do CSTDI/IFPB, ou seja, são aquelas que visam possibilitar a formação específica 


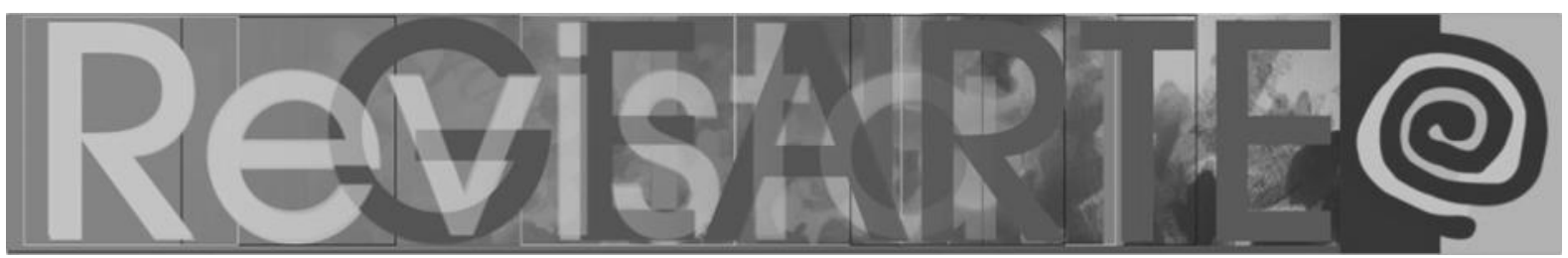

do designer de interiores. Entre essas disciplinas, a oficina de plástica, contém em sua ementa, elementos da linguagem visual objetivando desenvolver no estudante a criatividade.

Nesse contexto, Costa, Nascimento Júnior e Andrade (2016) afirmam que o campo disciplinar do ensino em design de interiores, especificamente em disciplinas que exigem o desenvolvimento do processo criativo, não basta apenas fundamentação em áreas de pedagogia e didática. O ensino de práticas projetuais, sejam elas o desenvolvimento de ambientes completos, seja de objetos isolados, tem gerado discussões, questionamentos em que o foco principal se refere à questão: como se ensina a criar? (COSTA, NASCIMENTO JÚNIOR, e ANDRADE, 2016, p. 152).

A disciplina oficina de plástica do CSTDI/IFPB representa uma parte da estrutura principal do currículo do curso. Ministrada no primeiro semestre é fundamental para estabelecer uma base como resposta a ser desenvolvida pelo estudante no seu processo criativo. Ao final do curso, o sistema pedagógico pressupõe que o estudante possua as condições necessárias e relevantes para poder elaborar projetos de design de interiores (COSTA, NASCIMENTO JÚNIOR, e ANDRADE, 2016 p. 152).

As disciplinas história do design; história da arte e da arquitetura e história do mobiliário, aplicadas no $1^{\circ}, 2$ e $3^{\circ}$ períodos do curso CSTDI/IFPB, objetivam embasar o estudante nos conceitos teóricos e históricos que permitirão leituras de imagens e movimentos artísticos.

Além da exigência da competência em expressão gráfica, em que os estudantes devem adquirir a habilidade com as ferramentas do desenho, desde o esboço ou croqui, passando pelos instrumentos tradicionais, execução de modelos físicos até o domínio dos programas de computação gráfica, tais como o 


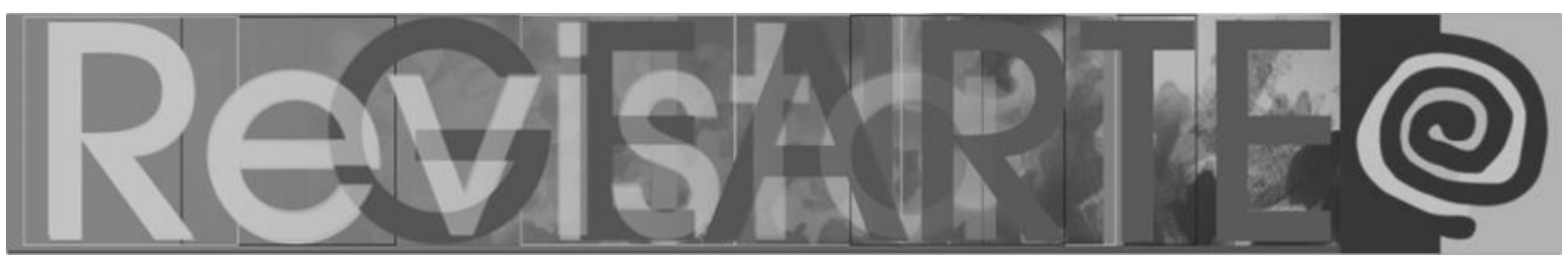

Sketchup ${ }^{5}$, O Auto $C A D^{6}$ e o Revit ${ }^{7}$, os estudantes devem progressivamente demonstrar suas habilidades em desenvolver a metodologia própria para o projeto de design de interiores, utilizar conceitos de ergonomia, conforto térmico, acústico e lumínico, sustentabilidade e acessibilidade, além, de demonstrar toda sua capacidade criativa nesse processo.

\section{A contribuição das artes visuais para o conceito de projeto}

$\mathrm{Na}$ aferição da contribuição das artes visuais para a concepção do conceito de projeto de design de interiores propomos a criação de um minicurso intitulado "Uso de imagens de obras de arte na formação do conceito do projeto de Design de Interiores" que teve a duração de 12 horas/aula, divididas em quatro dias, com a participação de 14 estudantes do CSTDI/IFPB, os quais foram distribuídos em quatro grupos para execução das atividades práticas, com o auxílio de duas monitoras, estudantes do CSTDI/IFPB concluintes do curso.

No minicurso foram propostas as seguintes atividades: (1) apresentação e descrição da(s) obra(s) de arte; (2) análise pré-iconográfica das imagens de obras de arte; (3) concepção e execução do painel conceitual; (4) geração de alternativas para um espaço comercial.

Foram apresentados conceitos sobre iconografia e descrição préiconográfica da imagem de obras de arte, com foco na leitura dos elementos formais da linguagem visual (forma, cores, texturas, linhas, pontos, luz, sombra,

5 SketchUp é um software proprietário fornecido pela Google desde 2006. Criado para proporcionar uma experiência próxima do desenho à mão livre e de modelagens com objetos reais, o SketchUp se destaca pela rapidez e facilidade de criação de objetos e estudos volumétricos (ARAÚJO JÚNIOR, 2015).

6 AutoCAD é um software do tipo CAD - computer aided design ou desenho assistido por computador - criado e comercializado pela Autodesk, Inc. desde 1982. É utilizado principalmente para a elaboração de peças de desenho técnico em duas dimensões (2D), para criação de modelos tridimensionais (3D), e desenhos arquitetônicos (ARAÚJO JÚNIOR, 2015).

7 O software Revit é utilizado para a BIM (Modelagem de Informações de Construção). Por meio das suas ferramentas é possível usar o processo para fazer modelos para planejar, projetar, construir e gerenciar edifícios e infraestruturas (www.plataformacad.com).

ARAÚJO JÚNIOR, Aarão Pereira de; COSTA, Robson Xavier da.

326

Artes visuais e design de interiores: iconografia e o conceito de projeto.

Revista GEARTE, Porto Alegre, v. 7, n. 2, p. 316-333, maio/ago. 2020.

Disponível em: http://seer.ufrgs.br/gearte 


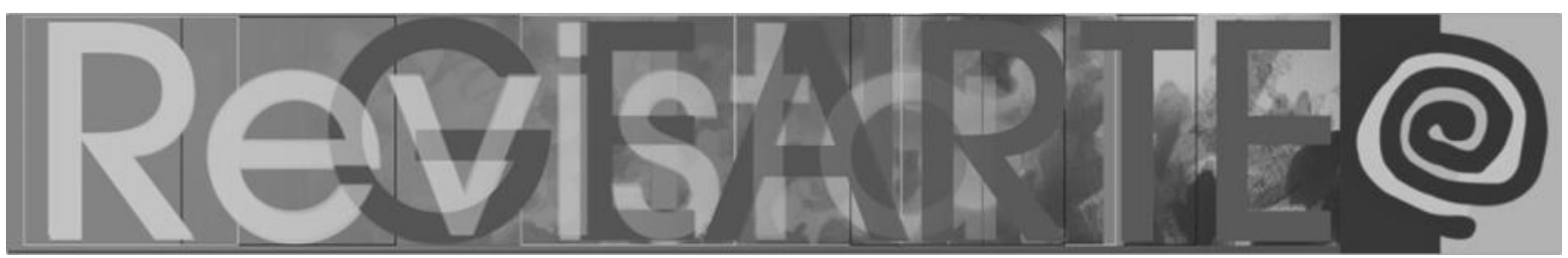

volume, materiais, etc.). A turma foi dividida em quatro grupos, cada grupo recebeu a reprodução de uma obra de arte específica, no caso, uma pintura para fazer a descrição pré-iconográfica dessa obra. As imagens das obras de arte selecionadas pelo grupo foram: Grande Plano Vermelho (1921), de Piet Mondrian (1872-1944); Las Meninas (1656), de Diego de Velázquez (1599-1660); O Grito (1893), de Edward Munch (1863-1944); Persistência da Memória (1931), de Salvador Dalí (1904-1989); A Tristeza do Rei (1952), de Henri Matisse (1863-1954).

Com base no painel conceitual, os grupos criaram projetos de design de interiores para um espaço residencial. Os espaços sorteados entre os grupos foram: cozinha, quarto, sala e home-office. Os trabalhos foram apresentados como desenhos e esboços.

Apresentamos ao grupo de estudantes do CSTDI/IFPB os conceitos de iconografia, com ênfase na descrição pré-iconográfica, necessária para analisar as imagens das obras em questão. Como exemplo da descrição pré-iconográfica destacamos a obra "Grande Plano Vermelho", de Piet Mondrian (Figura 3).

Figura 3 - Piet Mondrian (1872-1944): Composição com grande plano vermelho, amarelo, preto, cinza e azul, 1921. Coleção Gemeentemuseum Den Haag, Holanda

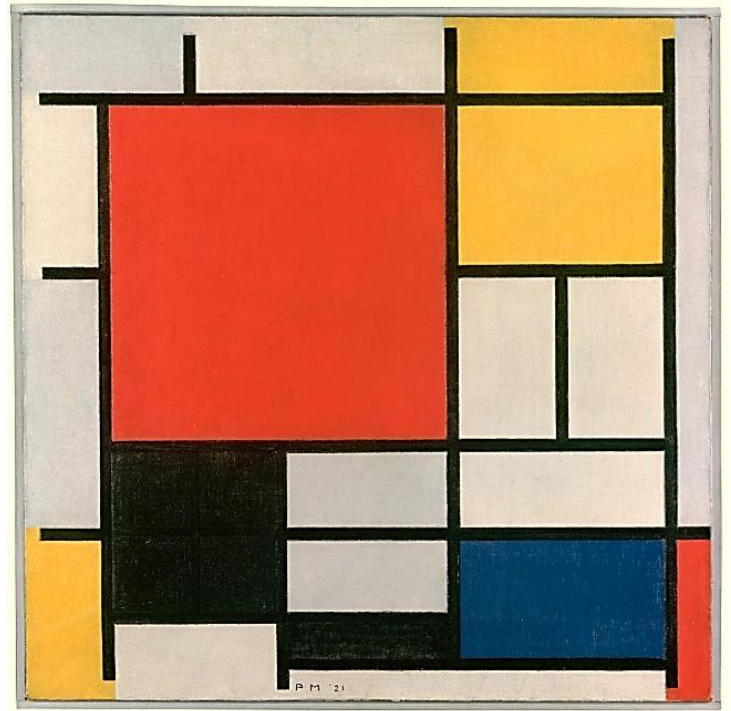

Fonte: https://www.hojeemdia.com.br/almanaque/mostra-no-ccbb-fazhomenagem-ao-pintor-mondrian-1.399408.

ARAÚJO JÚNIOR, Aarão Pereira de; COSTA, Robson Xavier da. 


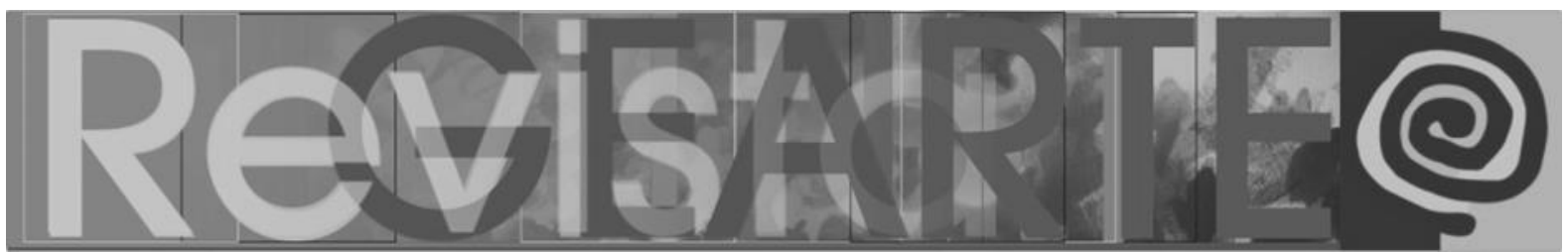

Posteriormente os estudantes apresentaram os painéis conceituais (exemplo - Figura 4) e os resultados dos projetos de design de interiores de uma cozinha usando essa obra como conceito (exemplos - Figuras 5).

Figura 4 - Painel conceitual a partir da leitura da imagem da obra "Grande Plano Vermelho"

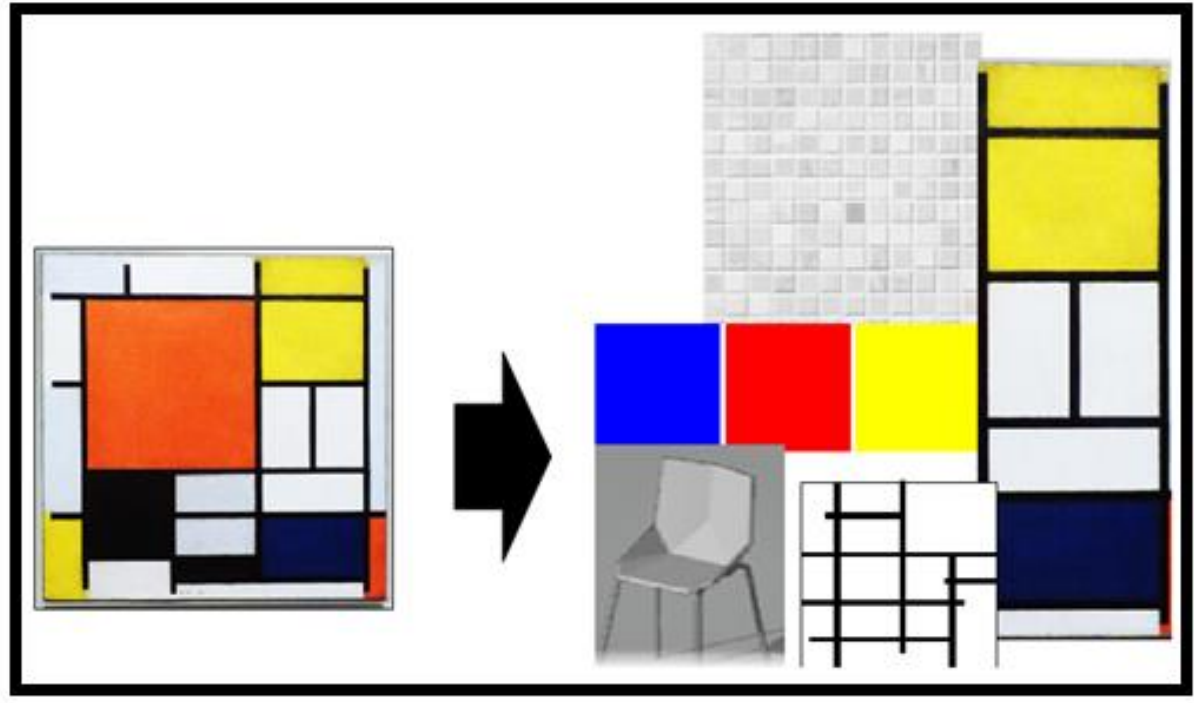

Fonte: acervo dos autores.

Figura 5 - Resultado do projeto de design de interiores a partir da leitura da imagem da obra "Grande Plano Vermelho"

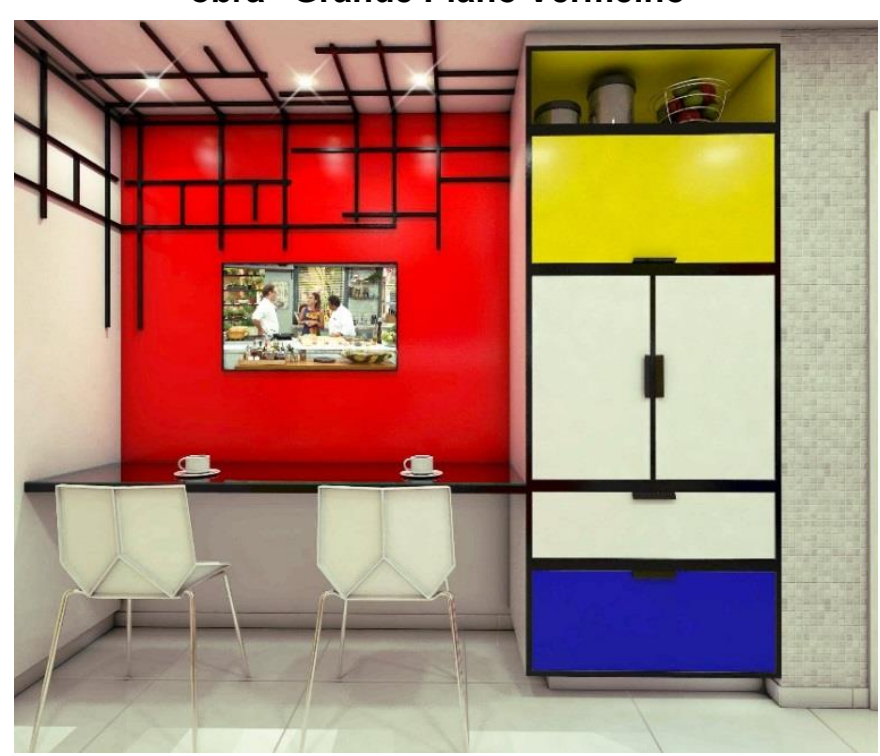

Fonte: acervo dos autores.

Em seguida, os grupos desenvolveram e apresentaram suas propostas baseadas na descrição pré-iconográfica e no painel conceitual (exemplos - figuras 


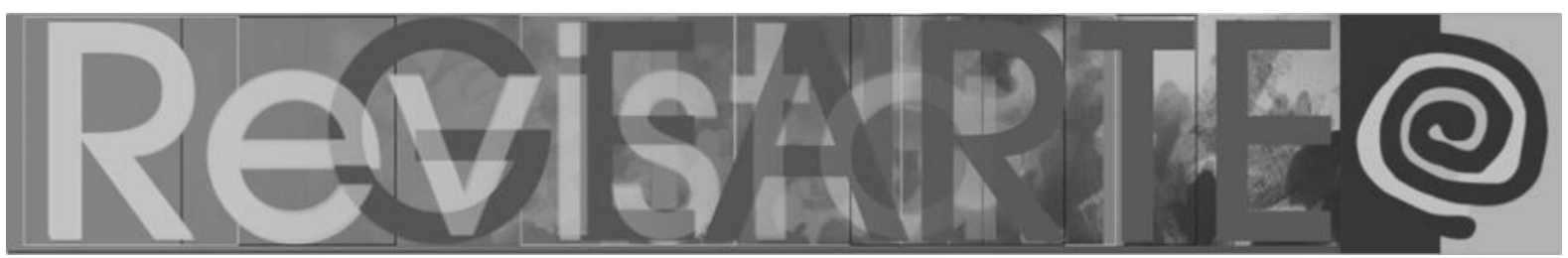

6 a 8) e os resultados (exemplos figuras 9 e 10) e responderam o questionário de avaliação do minicurso, na análise das respostas dos estudantes identificamos a importância da análise por meio da descrição pré-iconográfica para a concepção de um projeto de design de interiores.

Figura 6 - Painel conceitual a partir da leitura da imagem da obra "A Persistência da Memória"

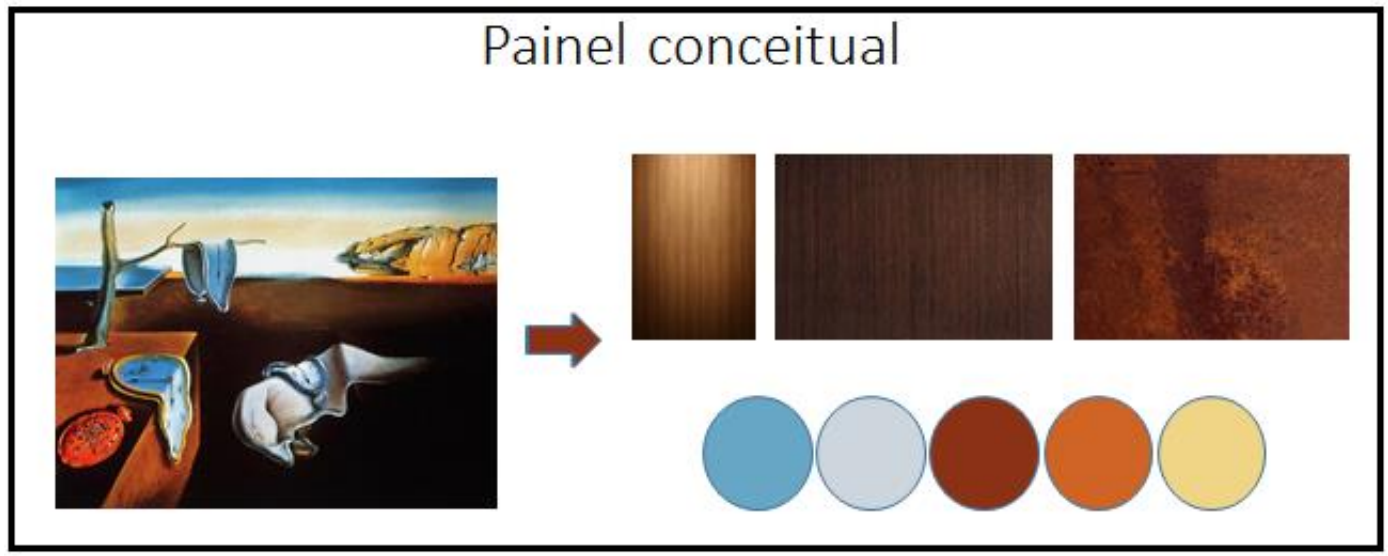

Fonte: acervo dos autores.

Figura 7 - Análise pré-iconográfica a partir da imagem da obra "A Tristeza do Rei"

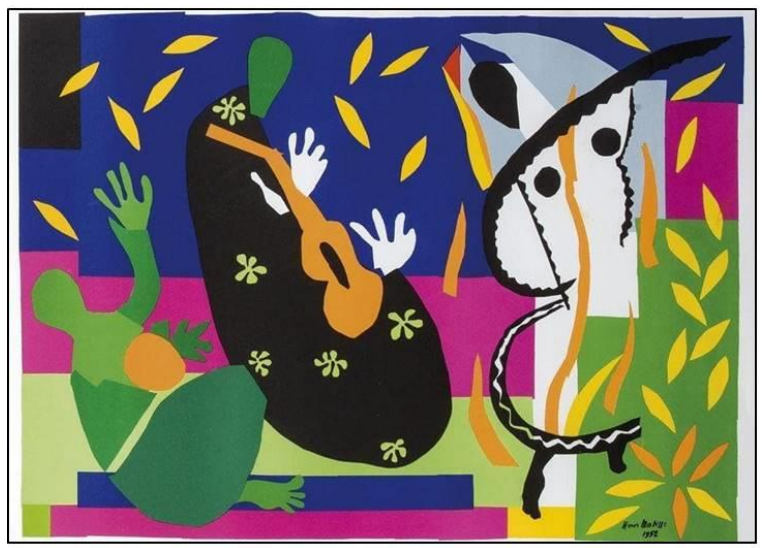

Cores primárias (amarelo, azul, vermelho). Secundárias e complementares.

Linhas retas e curvas.

Formas orgânicas e geométricas.

Assimetria.

A riqueza de cores, elementos e formas variadas nos transmite a sensação de movimento.

Branco e preto como a quebra de todas as cores.

Tons neutros.

Fonte: acervo dos autores. 


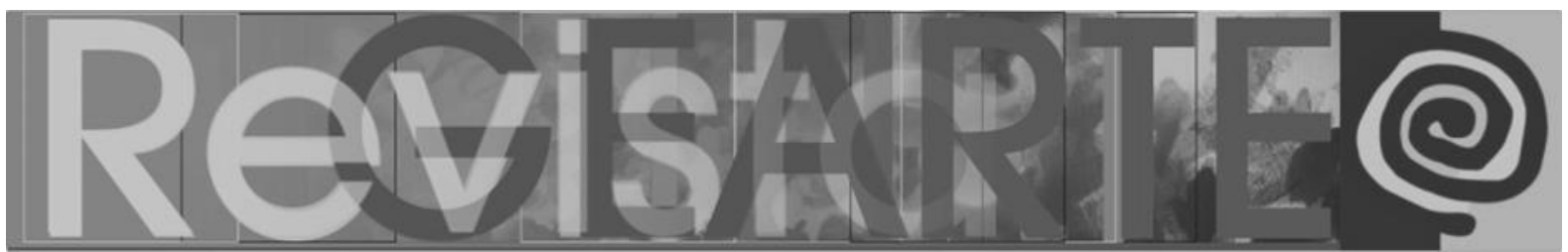

Figura 8 - Painel conceitual a partir da leitura da imagem da obra "A Tristeza do Rei"

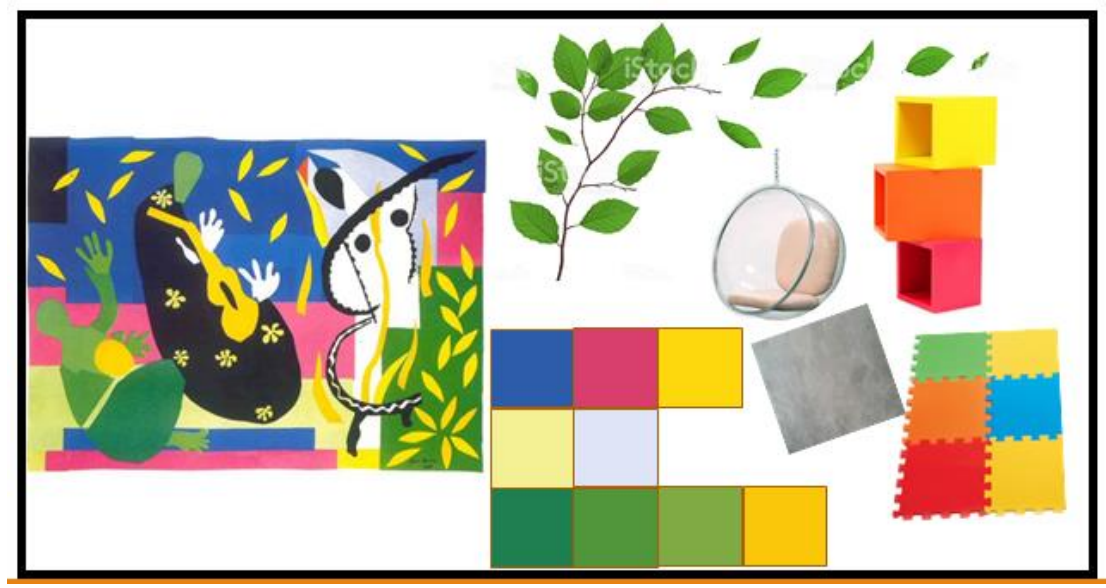

Fonte: acervo dos autores.

Figura 9 - Resultado do projeto de design de interiores a partir da leitura da imagem da obra "A Persistência da Memória"

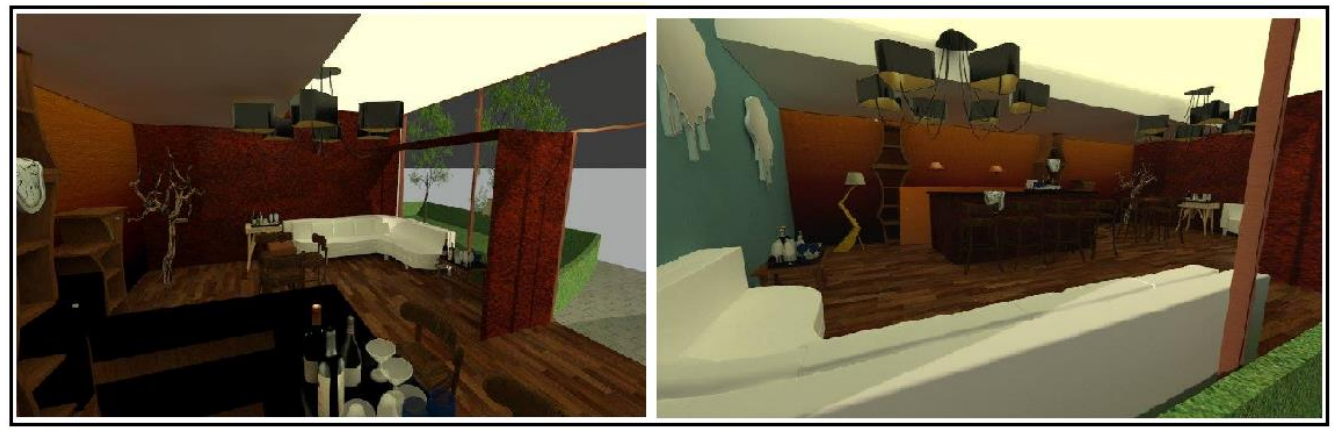

Fonte: acervo dos autores.

Figura 10 - Resultado do projeto de design de interiores a partir da leitura da imagem da obra "A Tristeza do Rei".
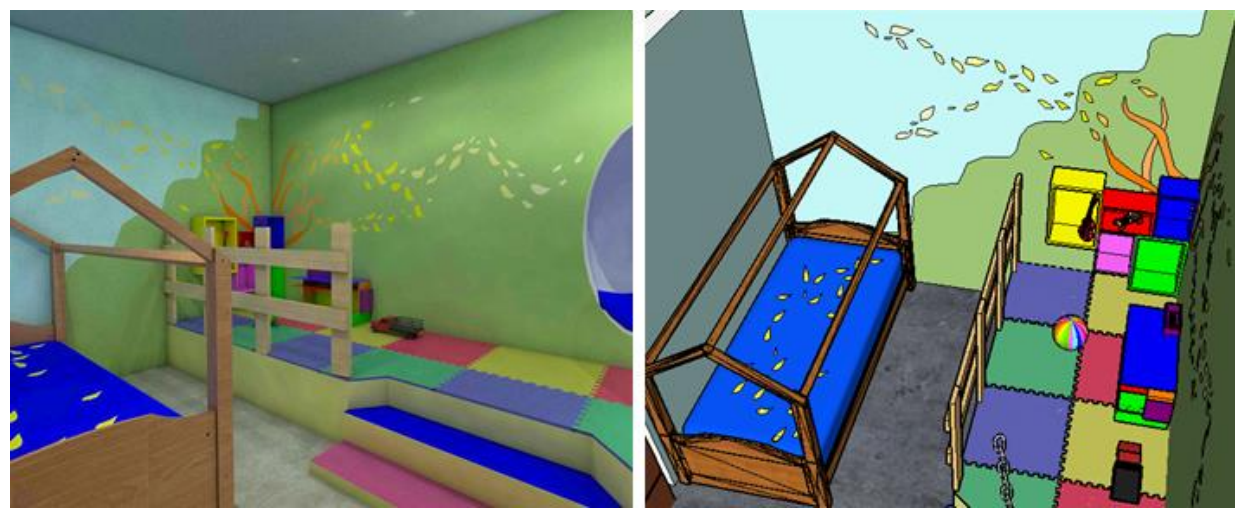

Fonte: acervo dos autores.

Destacamos como resultado do minicurso a importância do uso da análise pré-iconográfica, que possibilitou estabelecer descrições detalhadas as quais 


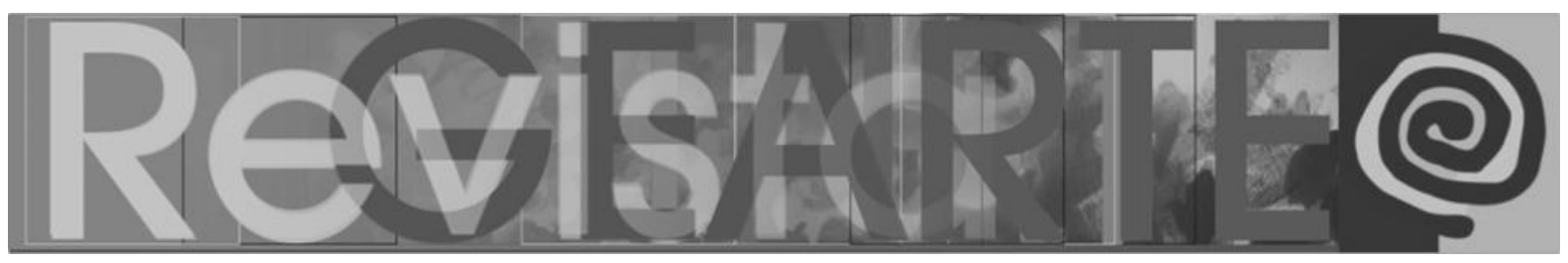

permitiram conceber o conceito que posteriormente foi expresso em forma de projeto de design de interiores.

Essa atividade projetual foi desenvolvida de modo simplificado, alguns requisitos básicos do projeto de design de interiores, vistos nas disciplinas, foram suprimidos, por questão de tempo, já que o minicurso teve a duração de 12 horas/aula. Portanto, o programa de necessidades, envolvendo variáveis como ergonomia e conforto térmico, acústico e lumínico, foi suprimido nas propostas. Partimos de uma planta-baixa existente de um ambiente pré-definido, onde o estudante, com os dados obtidos da descrição pré-iconográfica, concretizados no painel conceitual baseados em imagens de obras de arte.

\section{Considerações finais}

Por meio desta pesquisa, a partir da análise da prática de um minicurso aplicado a uma turma heterogênea de estudantes do CSTDI/IFPB, respondemos a pergunta: os elementos da linguagem visual proporcionaram a compreensão do conceito de projeto de design de interiores nas disciplinas do eixo central do Curso de Graduação em Design de interiores do IFPB? Ao observarmos que o uso do método da descrição pré-iconográfica aplicada ao conceito de projeto de design de interiores no CSTDI/IFPB foi determinante para a identificação dos elementos primários das imagens utilizadas, possibilitando o desenvolvimento do conceito utilizado nos projetos de design de interiores apresentados pelos estudantes.

A descrição pré-iconográfica se mostrou um instrumento auxiliar eficaz na elaboração de projetos de design de interiores, os elementos da linguagem visual serviram de referências para o projeto de design de interiores.

Ressaltamos que o estudo da iconografia e iconologia, podem ser inseridos nas ementas de uma das disciplinas de história da arte, a partir do $1^{\circ}$ período do CSTDI/IFPB, ampliando o repertório dos estudantes. 


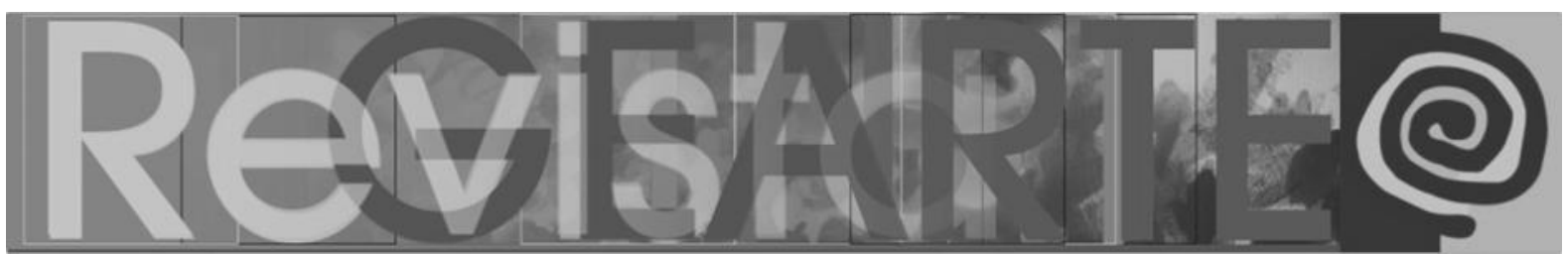

Os resultados desta pesquisa nos levam a inferir que o estudo dos elementos da linguagem visual e das imagens de obras de arte podem contribuir efetivamente para a compreensão do "conceito" aplicado ao projeto de design de interiores, por meio do uso da descrição pré-iconográfica.

\section{Referências}

ARAUJO JUNIOR, Aarão Pereira de. Panorama da expressão gráfica: o ensino integrado em um ambiente sociointeracionista. João Pessoa: IFPB, 2015.

BRASIL. Ministério da Educação. Catálogo Nacional de Cursos Superiores de Tecnologia. Brasília, 2016.

COSTA, Robson Xavier. Ensino de artes visuais: autorreflexão sobre o ato de educar. In: CARVALHO, Lívia Marques; SILVA, Maria Betânia e; COSTA, Robson Xavier. (Orgs.). Tessituras: experiências e vivências em artes visuais. João Pessoa. UFPB, 2015. p. 165-180.

COSTA, Roberta Xavier da; NASCIMENTO JÚNIOR, José Batista do; ANDRADE, Naiade. A experiência do atelier de Plástica no processo de ensino e aprendizagem para a formação do Designer de Interiores. In: CARVALHO, Lívia Marques; SILVA, Maria Betânia e; COSTA, Robson Xavier. (Orgs.). Tessituras: experiências e vivências em artes visuais. João Pessoa: UFPB, 2015.

GIBBS, Jenny. Design de interiores: guia útil para estudantes e profissionais. Barcelona: Gustavo Gili, 2010.

HIGGINS, lan. Planejar espaços para o design de interiores. Barcelona: Gustavo Gili, 2015.

IFPB. Plano Pedagógico do Curso Superior de Tecnologia em Design de Interiores (PPC/CSTDI). João Pessoa: IFPB, 2015.

MEIRA, Flora. Entrevista concedida a Aarão Pereira de Araújo Júnior por e-mail. João Pessoa/PB, 18 de junho de 2017.

OLIVEIRA, Jô; GARCEZ, Lucília. Explicando a arte: uma iniciação para entender e explicar as artes visuais. Rio de Janeiro: Ediouro, 2001.

PANOFSKY, Erwin. Iconografia e iconologia: uma introdução ao estudo da arte da Renascença. In: PANOFSKY, Erwin. Significado nas artes visuais. Tradução de Maria Clara F. Kneese e Jacó Guinsburg. 2. ed. São Paulo: Perspectiva, 1986, p. 47-87.

PIÑÓN, Helio. Teoria do projeto. Tradução de Edson Mahfuz. Porto Alegre: Livraria do Arquiteto, 2006.

PMBOK - PROJECT MANAGEMENT INSTITUTE. A guide to the project management body of knowledge (PMBOK Guide). Project Management Institute, Inc., 2008. Disponível em: https://www.pmi.org/pmbok-guide-standards. Acesso em: 17 mar. 2018.

SANT'ANNA, Armando. Propaganda: teoria, técnica e prática. São Paulo: Pioneira, 1989.

VALLE, André Bittencourt do et al. Fundamentos do gerenciamento de projetos. Rio de Janeiro: FGV, 2007. 


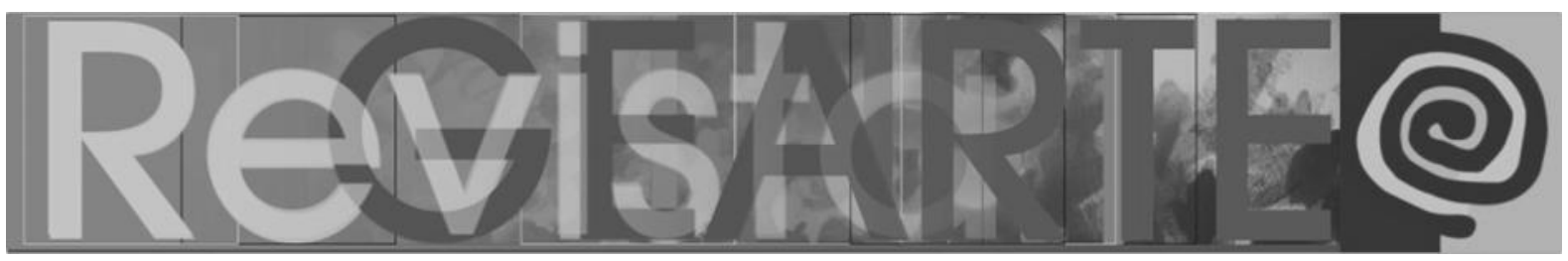

Aarão Pereira de Araújo Júnior

Possui graduação em Desenho Industrial pela Universidade Federal de Campina Grande (1991), mestrado em Educação pela Universidade Federal da Paraíba (2005), doutorado em Educação pela Universidade Federal da Paraíba (2011) e pós-doutorado em Artes Visuais pelo PPGAVUFPB/UFPE. É professor efetivo do Instituto Federal de Educação, Ciência e Tecnologia da Paraíba - IFPB. Tem experiência nas áreas de Desenho Industrial, Ergonomia e Educação, atuando principalmente com antropometria, acessibilidade, design do produto e processos de ensino e aprendizagem.

Orcid: https://orcid.org/0000-0003-1229-6147

E-mail: aaraoaraujo@yahoo.com.br

Currículo: http://lattes.cnpq.br/2881518626704499

\section{Robson Xavier da Costa}

Artista visual, curador e professor/pesquisador em artes visuais. Doutor em Arquitetura e Urbanismo (PPGAU UFRN); Mestre em História (PPGH UFPB). Realizou Estágio Sanduíche na Universidade do Minho, Portugal e na Universidad de Granada - Espanha; Especialista em Educação Especial (CE UFPB); Licenciado em Educação Artística - Artes Plásticas (UFPB) e Pósdoutor pelo PGEHA MAC USP. Docente/Pesquisador no Departamento de Artes Visuais da Universidade Federal da Paraíba (UFPB) e nos Programas de Pós-Graduação em Artes Visuais (PPGAV UFPB/UFPE - Atual Coordenador) e de Computação, Comunicação e Arte (PPGCCA UFPB). Membro da ABCA, da ANPAP e da FAEB.

Orcid: https://orcid.org/0000-0003-3012-3741

E-mail: robsonxavierufpb@gmail.com

Currículo: http://lattes.cnpq.br/3706411790927848

Recebido em 22 de dezembro de 2018 Aceito em 15 de maio de 2020 